\title{
A summary of Evaluation of Asthma Control in Children Using Childhood-Asthma Control Test (CACT) and Asthma Therapy Assessment Questionnaire (ATAQ)
}

\author{
AR Somashekar*, KG Ramakrishnan \\ Department of Pediatrics, MS Ramaiah Medical College and Hospitals, Bengaluru, Karnataka, India
}

Article Info

Article Notes

Received: March 12, 2018

Accepted: March 5, 2019

\section{${ }^{*}$ Correspondence:}

Dr. Somashekar AR, Department of Pediatrics, MS Ramaiah Medical College and Hospitals, Bengaluru, Karnataka, India; Email: s_arshekar2002@yahoo.com

C 2019 Somashekar AR. This article is distributed under the terms of the Creative Commons Attribution 4.0 International License.
Asthma is a chronic disease of the airway which is associated with lifelong morbidity with a Disability adjusted life years of up to $500^{1}$.The goal of asthma care is hence to achieve and maintain asthma control'2. In order to do this, children need to visit medical practitioners and paediatricians periodically to assess asthma control.

Global initiative of asthma lays down certain criteria Known as the GINA criteria which involve pulmonary function tests ${ }^{3}$. However, performing pulmonary function tests repeatedly in resource poor settings becomes cumbersome. An alternative, organised clinical tool to assess asthma control is hence required.

This study was conducted to test the efficacy of two such tools, Childhood asthma control test and asthma therapy assessment questionnaire since previous studies have yielded conflicting results $^{4-5}$.

The study conducted by AR et al. found the efficacy of c-Act to be fair and acceptable ${ }^{6}$. However the findings of the study were not as promising as other studies ${ }^{7}$. Hence, there is a possibility of higher efficacy of the tool at a different cut off value as suggested by the study conducted by Yixinshu et $\mathrm{al}^{8}$, which showed that a different cut-off level is more suitable for Hispanic children in California. Findings in this study were similar, the statistical parameters of C-ACT at cut-off score 20 were more significant than the original cut off score of 19. The findings of the study however were limited by the cultural diversity of the participants giving rise to linguistic barriers.

ATAQ on the other hand was found to be not very effective at predicating asthma control and was found to require structural modifications.

The study hence concluded that the childhood asthma control test is a reliable questionnaire to predict asthma control.

\section{References}

1. The global asthma report 2014. Available from http://www.globalasthmareport. org/burden/burden.php. Dae last updated December 2017, Date last accessed: march 2018.

2. Bateman ED, Hurd SS, Barnes PJ, et al. Global strategy for asthma management and prevention: GINA executive summary. EurRespir J. 2008; 31: 143-78.

3. Global initiative for asthma,Pocket guide for asthma management and prevention. Available from www.ginasthma.org. Date last updated: December 2013, Date last accessed: May 2014. 
4. Yu HR, Niu CK, KuoHC,Ka-YT, et al Comparison of the Global Initiative for Asthma guideline-based Asthma Control Measure and the Childhood Asthma Control Test inevaluating asthma control in children. Paediatrics and Neonatology. 2010. doi:10.1016/S18759572(10)60053-8

5. Andrew H. Liu, Robert ZeigerChristineSorkness,ToddMahr, et al. Development and cross-sectional validation of the Childhood Asthma Control Test, NC American academy of allergy asthma and immunology. J Allergy ClinImmunol. 2007; 119: 817-25.
6. Somashekar AR, Ramakrishnan KG. Evaluation of Asthma Control in Children Using Childhood-Asthma Control Test (C-ACT) and Asthma Therapy Assessment Questionnaire (ATAQ).

7. Chalise SP, Bhatta NK, Singh RR, et al. Assessment of control of bronchial asthma in children using Childhood Asthma Control Test. indian J Chest Dis Allied Sci. 2014 Apr-Jun; 56(2): 75-8.

8. Shi Y, Tatavoosian AV, Aledia AS, et al. The Cut-points for Asthma Control Tests are higher in Mexican Children In orange country, California. Ann Allergy asthma immunol. 2012 August; 109(2): 108-113. 